\title{
Pengaruh Medan Elektromagnet terhadap Partikel Dirac dan Klein-Gordon dalam Potensial Penghalang Periodik Satu Dimensi
}

\begin{tabular}{l}
\hline Received \\
26 November 2018 \\
Revised \\
19 March 2020 \\
Accepted for Publication \\
26 April 2020 \\
Published \\
15 June 2020
\end{tabular}

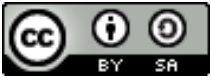

This work is licensed under a Creative Commons AttributionShareAlike 4.0 International License

\author{
A Romadani ${ }^{{ }^{*}}$ dan E Rani ${ }^{1}$ \\ 1. Jurusan Fisika, Fakultas Sains dan Teknologi, Universitas Islam Negeri Maulana Malik Ibrahim \\ Malang, Jl. Gajayana No. 50, Malang, 6514, Indonesia. \\ *E-mail: arista.romadani@uin-malang.ac.id
}

\begin{abstract}
A Bosonic particle and zero mass Dirac acting on a one-dimensional barrier potential have been studied in relativistic quantum mechanics using the Dirac and Klein-Gordon equation. The equations are modified due to the influence of the electromagnetic fields and the matrix approach has been applied to obtain the representation of energy and the eigen spinor. Especially for Dirac particles, the Dirac Hamiltonian form is similar to the harmonic oscillator, so the representation of energy is an extension of the harmonic oscillator energy. In addition, the eigenfunctions involved positive energy and negative energy that moved exponentially when passed through a potential barrier.

Keywords: Klein-Gordon, Dirac, elektromagnetic, quantum.
\end{abstract}

\section{Pendahuluan}

Graphene atau grafena merupakan karbon allotrope dalam bentuk dua dimensi yang memiliki struktur kisi segienam atau heksagonal dengan komposisi atom karbon. Karena komposisi ini, karakteristik grafena sama seperti karbon aktif sehingga mengakibatkan susunan kisinya dapat bekerja seperti penyaring. Ikatan atom karbon pada grafena merupakan ikatan yang kuat karena tiap satu atom karbon memiliki 1 ikatan sigma di antara tiga atom karbon tetangganya. Grafena memiliki karakteristik yang tidak biasa yaitu memiliki kekuatan 200 kali lebih besar dibandingkan baja dengan tingkat fleksibilitas yang sangat tinggi. Selain itu, grafena juga merupakan bahan konduktor yang sangat baik karena transport elektron yang baik dan juga transparan [1].

Keunikan karakteristik grafena lebih lanjut diaplikasikan sebagai baterai grafena yang terdiri dari superkapasitor. Baterai ini sangat ringan dan dapat digunakan pada kendaraan seperti mobil dan pesawat. Grafena juga efektif digunakan sebagai bahan semikonduktor pengganti beberapa material mahal yang digunakan untuk membuat sebuah prosesor komputer. Struktur heksagonal grafena sangat efektif dalam proses penyaringan. Membran grafena oksida sangat efektif sebagai filter khususnya untuk cairan dan gas $[2,3]$. 
Akhir-akhir ini realisasi grafena dengan lapisan tunggal yang stabil dan juga lapisan ganda telah membangkitkan minat yang besar untuk mengkaji sifat elektroniknya. Eksistensi sifat konduktif dari grafena memungkinkan pengembangan perangkat nanoelektronik berbasis karbon. Perilaku pembawa muatan pada lembaran grafena lapisan tunggal yang lebar merupakan partikel-partikel tanpa sifat kiralitas, relativistik dengan kecepatan cahaya yang sama dengan kecepatan Fermi kristal $(v F \approx$ $c / 300$ ), dan dispersi linier tanpa celah yang dekat dengan $K$ dan $K_{0}$ poin [4,5,6]. Salah satu konsekuensinya bahwa graphene satu lapisan merepresentasikan efek kuantum Hall yang tidak biasa dimana kondisi plateau kuantum Hall muncul sebesar setengah bulat dari $\left(4 e^{2} / \hbar\right)$ [7]. Ketiadaan energi gap dan sifat kiral dari keadaan elektronik, baik pada grafena lapisan tunggal maupun ganda, mengarahkan kajian lebih lanjut pada fenomena seperti tunneling pada partikel Klein-Gordon yang merupakan transmisi pembawa sempurna melalui penghalang potensial [8].

Penelitian sebelumnya menggunakan potensial penghalang yang bergerak secara periodik untuk mengkaji hubungan dispersi untuk fermion tak bermassa yang digambarkan oleh persamaan Dirac dan untuk boson spin nol yang dijelaskan oleh persamaan Klein-Gordon, bergerak dalam dua dimensi dan dengan adanya potensi periodik satu dimensi [4,9]. Untuk fermion tak bermassa, hubungan dispersi menunjukkan energi gap dan momentum nol yang bergerak ke arah yang sejajar dengan penghalang yang sesuai dengan paradoks Klein. Fermion tersebut bersesuaian dengan karakteristik grafena dimana partikel pembawa bersifat relativistik terhadap kecepatan cahaya yang direpresentasikan melalui kecepatan $[10,11]$.

Penyelesaian persamaan Klein-Gordon untuk partikel bermuatan dengan variasi medan elektromagnetik bisa dilakukan dengan menggunakan transformasi Laplace [12]. Penelitian lainnya dalam menyelesaian persamaan Dirac dan Klein-Gordon dengan potensial penghalang yang bergerak dengan kecepatan konstan $v$, digunakan transformasi Lorentz untuk mengubah bentuk potensialnya ke dalam bentuk yang tidak bergantung waktu sehingga didapatkan koefisien refleksi dan transmisi [13]. Selain itu, solusi persamaan Dirac dalam pengaruh medan elektromagnetik yang konstan berhasil diselesaikan dan menghasilkan solusi fungsi gelombang dalam bentuk polinomial Hermite [14,15].

Fenomena fisika akan lebih menarik apabila partikel bergerak dalam suatu sistem yang dipengaruhi medan atau dalam kondisi yang lebih kompleks, semisal sistem beberapa partikel dimana ada interaksi antar partikel dan sistem yang mendapat pengaruh medan elektromagnet eksternal $[16,17,18]$. Sejauh ini, penelitian-penelitian yang ada masih membahas satu partikel baik fermion maupun boson berada dalam sistem potensial penghalang yang bergerak secara periodik tanpa ada pengaruh apapun. Berangkat dari penelitian terdahulu [4], studi berkenaan hubungan dispersi fermion tak bermassa dan boson spin nol dalam sistem potensial penghalang yang bergerak periodik dan dalam pengaruh medan elektromagnetik perlu untuk dikaji.

\section{Metode Penelitian}

Metode penelitian yang digunakan adalah metode analitik dengan mengonstruksi model matematis dan memperoleh penyelesaian yang merepresentasikan kasus potensial penghalang satu dimensi untuk partikel Dirac dan Klein-Gordon dengan adanya pengaruh medan elektromagnetik. Secara garis besar proses pencarian solusi atas masalah yang telah dipaparkan dilakukan dengan memodelkan sistem potensial penghalang periodik satu dimensi, kemudian berangkat dari persamaan Schrödinger untuk kasus potensial penghalang baik untuk fermion dan boson, dilakukan modifikasi persamaan KleinGordon dan Dirac akibat adanya medan elektromagnetik. Selanjutnya dengan merumuskan formulasi persamaan Hamiltonian termodifikasi akibat medan elektromagnet untuk model potensial penghalang satu dimensi dari masing-masing daerah potensial dan menentukan fungsi keadaan (nilai eigen) dan representasi energi dari potensial penghalang termodifikasi akibat medan elektromagnet baik untuk partikel fermion dan boson.

\section{Hasil dan Pembahasan}

3.1. Persamaan Klein-Gordon

Persamaan Schrodinger relativistik satu dimensi adalah

$$
\left(\nabla^{2}-\frac{1}{c^{2}} \frac{\partial^{2}}{\partial t^{2}}-\frac{m^{2} c^{2}}{\hbar^{2}}\right) \psi(x, t)=0,
$$


disebut juga dengan persamaan Klein-Gordon [19]. Keberadaan medan elektromagnet mengakibatkan persamaan (1) menjadi

$$
\left(D_{\mu} D^{\mu}+m^{2} c^{2}\right) \psi(x, t)=0
$$

Rapat Lagrangian dapat dinyatakan dengan persamaan $\mathcal{L}=\left(D_{\mu} \psi\right)^{*} D^{\mu} \psi-m^{2} \psi^{*} \psi[20]$, bentuk spinor diasumsikan seperti pada persamaan berikut

$$
\left(\begin{array}{l}
\xi_{1} \\
\xi_{2}
\end{array}\right)=\frac{1}{2}\left(\begin{array}{c}
\psi+\frac{i}{m} D_{0} \psi \\
\psi-\frac{i}{m} D_{0} \psi
\end{array}\right),
$$

dengan $D_{0}=\partial_{0}+i e \phi$ dan $\boldsymbol{D}=\Delta-i e \boldsymbol{A}$. Persamaan fungsi eigen pada persamaan (3) dinyatakan dengan

$$
i D_{0} \xi=H \xi
$$

dimana bentuk Hamiltoniannya adalah

$$
H=-\frac{\boldsymbol{D}^{2}}{2 m}\left(\sigma_{1}+i \sigma_{2}\right)+m \sigma_{3}
$$

dengan $\sigma_{i}$ merupakan matriks Pauli. Persamaan (5) disubstitusikan ke persamaan (4) menghasilkan solusi yang tidak dapat diselesaikan secara langsung dengan mudah karena persamaannya dalam komponen vektor-4. Untuk memperoleh solusi tersebut, salah satu metode yang digunakan melalui pendekatan untuk kasus potensial penghalang. Anggap partikel Klein-Gordon bergerak searah sumbu $z$ melewati potensial tangga satu dimensi dengan potensial $V_{0}$ sehingga fungsi potensial periodiknya dituliskan sebagai $V(z)=V_{0} \Theta(z)$ sebagaimana pada Gambar 1 .

Persamaan Schrodinger sistem dinyatakan dengan

$$
\left[\Delta^{2}-m^{2}\right] \psi(z)=V(z)-E \psi(z),
$$

sebagaimana kasus dalam mekanika kuantum, solusi dari sistem persamaan (6) ketika $E>V_{0}$ dapat dinyatakan dengan

$$
\psi(z)=\Theta(-z)\left[a e^{i p z}+b e^{-i p z}\right]+\Theta(z) d e^{i p^{\prime} z},
$$

dengan $p=\sqrt{E^{2}-k^{2}}$ dan $p^{\prime}=\sqrt{\left(E-V_{0}\right)^{2}-k^{2}}$.

Nilai koefisien refleksi dan transmisi pada kasus potensial penghalang satu dimensi adalah

$$
R=|b|^{2}=\frac{(1-\chi)^{2}}{(1+\chi)^{2}} \quad \text { dan } \quad T=|d|^{2} \chi=\frac{4 \chi}{(1+\chi)^{2}} .
$$

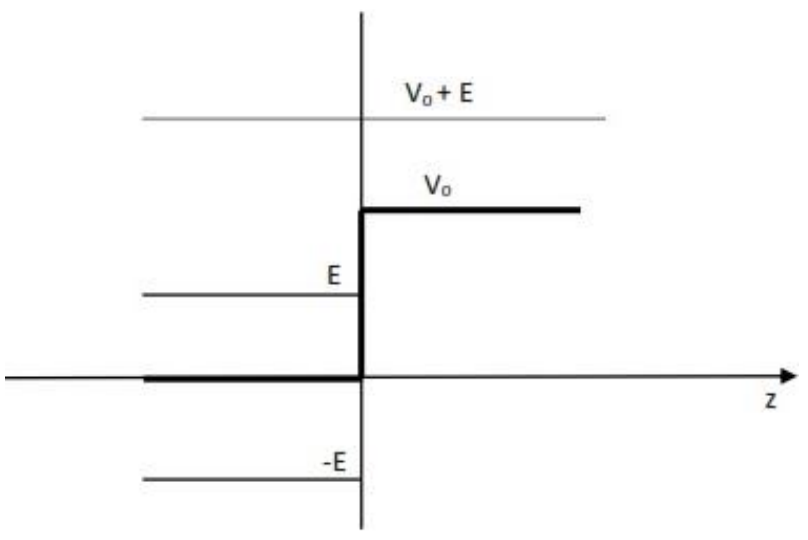

Gambar 1. Potensial tangga satu dimensi. 


\subsection{Persamaan Dirac dengan Pengaruh Medan Elektromagnet}

Persamaan kuantum relativistik menurut Dirac adalah

$$
i \hbar \frac{\partial \psi}{\partial t}=\left\{-i c \hbar \alpha \nabla+\beta m c^{2}\right\} \psi
$$

dengan $\alpha$ dan $\beta$ konstanta yang memenuhi $\alpha^{2}=\beta^{2}=1$ [18]. Selanjutnya persamaan (9) dapat dituliskan menjadi bentuk

$$
i \hbar \gamma^{\mu} \frac{\partial \psi(x)}{\partial x^{\mu}}-m c \psi(x)=0
$$

persamaan (10) yang dikenal dengan persamaan Dirac. Apabila persamaan Dirac diberi pengaruh medan elektromagnetik, maka akan terjadi interaksi di antara keduanya dan beberapa kuantitas seperti momentum dan turunan kovarian mengalami transformasi menjadi

$$
\left[i \hbar \frac{\partial}{\partial t}-e \phi-c \boldsymbol{\sigma} \cdot\left(-i \hbar \nabla-\frac{e}{c} \boldsymbol{A}\right)-m c^{2} \beta\right] \psi=0
$$

[21], persamaan (11) dapat dituliskan menjadi bentuk matriks yaitu

$$
\left(\begin{array}{cc}
e \phi & c \boldsymbol{\sigma} \cdot\left(\boldsymbol{p}-\frac{e}{c} \boldsymbol{A}\right) \\
c \boldsymbol{\sigma} \cdot\left(-i \hbar \boldsymbol{\nabla}-\frac{e}{c} \boldsymbol{A}\right) & -2 m c^{2}+e \phi
\end{array}\right) \psi=E^{\prime} \psi,
$$

dengan $\boldsymbol{p}=-i \hbar \boldsymbol{\nabla}$ adalah momentum dan $E^{\prime}=E-m c^{2}$ merupakan energi elektron pada level di atas energi diam. Fungsi eigen dari persamaan (12) dinyatakan dalam bentuk dua komponen spinor pada persamaan (13) sebagai

$$
\psi=\left(\begin{array}{l}
\varphi_{1} \\
\varphi_{2}
\end{array}\right),
$$

dimana komponen besar $\varphi_{1}$ dan $\varphi_{2}$ terdiri dari dua komponen vektor yang menggambarkan dua partikel yang memiliki keadaan spin up dan spin down yaitu $\varphi_{1}=\left(\begin{array}{l}1 \\ 0\end{array}\right)$ dan $\varphi_{1}=\left(\begin{array}{l}0 \\ 1\end{array}\right)$.

Secara eksplisit persamaan (12) dituliskan dengan

$$
\begin{gathered}
e \phi \varphi_{1}+c \boldsymbol{\sigma} \cdot\left(\boldsymbol{p}-\frac{e}{c} \boldsymbol{A}\right) \varphi_{2}=E^{\prime} \varphi_{1} \\
c \boldsymbol{\sigma} \cdot\left(\boldsymbol{p}-\frac{e}{c} \boldsymbol{A}\right) \varphi_{1}+\left(-2 m c^{2}+e \phi\right) \varphi_{2}=E^{\prime} \varphi_{2}
\end{gathered}
$$

jika persamaan (15) disubstitusikan ke persamaan (14) maka diperoleh

$$
\varphi_{1}=\frac{1}{E_{-}+m c^{2}-e \phi} c \boldsymbol{\sigma} \cdot\left(\boldsymbol{p}-\frac{e}{c} \boldsymbol{A}\right) \varphi_{2}
$$

dan

$$
\varphi_{2}=\frac{1}{E_{+}+m c^{2}-e \phi} c \boldsymbol{\sigma} \cdot\left(\boldsymbol{p}-\frac{e}{c} \boldsymbol{A}\right) \varphi_{2},
$$

dengan $E_{ \pm}=E^{\prime} \pm m c^{2}$. Selanjutnya, nilai gauge Landau $\boldsymbol{A}=B(0, x, 0)$ sehingga diperoleh

$$
\boldsymbol{\sigma} \cdot\left(\boldsymbol{p}-\frac{e}{c} \boldsymbol{A}\right)=\left(\begin{array}{cc}
p_{3} & p_{-}-\frac{e}{c} B x \\
p_{+}+\frac{e}{c} B x & -p_{3}
\end{array}\right) .
$$


Berdasarkan persamaan (17) dan (18) maka diperoleh

$$
\varphi_{2}=\left(\begin{array}{c}
\frac{c p_{3}}{E_{+}+m c^{2}-e \phi} \\
\frac{c p_{+}+e B x}{E_{+}+m c^{2}-e \phi}
\end{array}\right),
$$

$\operatorname{untuk} \varphi_{1}=\left(\begin{array}{l}1 \\ 0\end{array}\right)$ dan

$$
\varphi_{2}=\left(\begin{array}{c}
\frac{c p_{-}-e B x}{E_{+}+m c^{2}-e \phi} \\
\frac{c p_{3}}{E_{+}+m c^{2}-e \phi}
\end{array}\right)
$$

untuk $\varphi_{1}=\left(\begin{array}{l}0 \\ 1\end{array}\right)$. Oleh karena itu, solusi untuk energi positif menjadi

$$
\begin{aligned}
& \psi^{(1)}=N\left(\begin{array}{c}
1 \\
0 \\
\frac{c p_{3}}{E_{+}+m c^{2}-e \phi} \\
\frac{c p_{+}+e B x}{E_{+}+m c^{2}-e \phi}
\end{array}\right), \\
& \psi^{(2)}=N\left(\begin{array}{c}
1 \\
\frac{c p_{-}-e B x}{E_{+}+m c^{2}-e \phi} \\
\frac{c p_{3}}{E_{+}+m c^{2}-e \phi}
\end{array}\right) .
\end{aligned}
$$

Dengan cara yang sama untuk solusi energi negatif diperoleh

$$
\varphi_{1}=\left(\begin{array}{l}
\frac{-c p_{3}}{E_{+}+m c^{2}-e \phi} \\
\frac{-c p_{+}+e B x}{E_{+}+m c^{2}-e \phi}
\end{array}\right) \quad \text { untuk } \varphi_{2}=\left(\begin{array}{l}
1 \\
0
\end{array}\right)
$$

dan

$$
\varphi_{1}=\left(\begin{array}{c}
\frac{-c p_{-}-e B x}{E_{+}+m c^{2}-e \phi} \\
\frac{-c p_{3}}{E_{+}+m c^{2}-e \phi}
\end{array}\right) \quad \text { untuk } \varphi_{2}=\left(\begin{array}{l}
0 \\
1
\end{array}\right),
$$

sehingga solusi fungsi eigen dalam spinor-4 diberikan

$$
\begin{aligned}
& \psi^{(3)}=N\left(\begin{array}{c}
\frac{-c p_{3}}{E_{+}+m c^{2}-e \phi} \\
\frac{-c p_{+}+e B x}{E_{+}+m c^{2}-e \phi} \\
1 \\
0
\end{array}\right) \\
& \psi^{(4)}=N\left(\begin{array}{c}
\frac{-c p_{-}-e B x}{E_{+}+m c^{2}-e \phi} \\
\frac{-c p_{3}}{E_{+}+m c^{2}-e \phi} \\
0 \\
1
\end{array}\right)
\end{aligned}
$$

dimana $p \pm=p_{1} \pm i p_{2}$. 


\subsection{Efek Penerobosan pada Potensial Penghalang Periodik}

Area I dan area III dapat diidentifikasikan dengan partikel Dirac fermion berspin nol, persamaan Hamiltonian dengan pengaruh medan elektromagnetik dapat dinyatakan sebagai berikut

$$
H_{D}^{(1)}=v_{f} \sigma \cdot \pi+\sigma_{2} e E x_{2}+\frac{1}{2} g \mu_{B} B \sigma_{3},
$$

dimana $v \approx 10^{6} \mathrm{~ms}^{-1}$ merupakan kecepatan Fermi, $\sigma=\left(\sigma_{1}, \sigma_{2}\right)$ matriks Pauli, dan $\mu_{B}$ adalah magneton Bohr [22]. Sementara itu, Hamiltonian untuk area II dengan massa berhingga yang disebabkan oleh gap sebesar $t^{\prime}$ sebagai berikut

$$
H_{D}^{(2)}=v_{f} \sigma \cdot \pi+\sigma_{2} e E x_{2}+t^{\prime} \sigma_{3}+\frac{1}{2} g \mu_{B} B \sigma_{3},
$$

Hamiltonian pada persamaan (27) dan (28) berperan penting untuk analisa lebih lanjut. Langkah pertama yang dilakukan dalam proses analisis adalah menetukan spektrum energi dan fungsi eigen pada setiap area.

\subsubsection{Spektrum I dan III}

Potensial vektor dalam gauge Landau dimisalkan $A\left(x_{1}, x_{2}\right)=\left(B x_{2}, 0\right)$, maka persamaan (27) diwujudkan dalam bentuk

$$
H_{D}^{(1)}=v_{f}\left(\begin{array}{cc}
0 & p_{1}-i p_{2}-\frac{e}{c} B x_{2}-\frac{i e E x_{2}}{v_{f}} \\
p_{1}+i p_{2}-\frac{e}{c} B x_{2}+\frac{i e E x_{2}}{v_{f}} & 0
\end{array}\right)+\frac{1}{2} g \mu_{B} B \sigma_{3},
$$

dengan memisalkan $\xi=1+\frac{i e E}{v B}$ dan $\bar{\xi}=1-\frac{i e E}{v B}$

$$
H_{D}^{(1)}=v_{f}\left(\begin{array}{cc}
0 & p_{1}-i p_{2}-\frac{\hbar}{l_{B}^{2}} \xi x_{2} \\
p_{1}+i p_{2}-\frac{\hbar}{l_{B}^{2}} \bar{\xi} x_{2} & 0
\end{array}\right)+\frac{1}{2} g \mu_{B} B \sigma_{3},
$$

dimana $l_{B}^{2}=\sqrt{\frac{e \hbar}{e B}}$ adalah panjang magnetik.

Untuk mendiagonalisasi persamaan (30) perlu dikenalkan operator anihilasi dan kreasi

$$
a=\frac{l_{B}}{\hbar \sqrt{2}}\left(p_{1}-i p_{2}-i \frac{\hbar}{l_{B}^{2}} \xi x_{2}\right) \quad \text { dan } \quad a^{\dagger}=\frac{l_{B}}{\hbar \sqrt{2}}\left(-i p_{1}-p_{2}+i \frac{\hbar}{l_{B}^{2}} \bar{\xi} x_{2}\right),
$$

dengan memenuhi aturan komutasi. Dengan menggunakan operator persamaan (31), maka Hamiltonan Dirac dapat dituliskan menjadi

$$
H_{D}^{(1)}=v_{f}\left(\begin{array}{cc}
\frac{1}{2} g \mu_{B} B & i \hbar \omega_{k} a^{\dagger} \\
-i \hbar \omega_{k} a & -\frac{1}{2} g \mu_{B} B
\end{array}\right),
$$

dengan $\omega_{k}=\sqrt{2} \frac{v_{f}}{l_{B}}$ merupakan frekuensi siklotron.

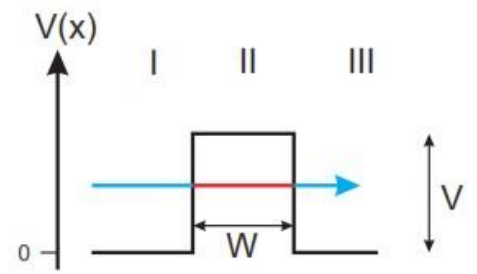

Gambar 2. Potensial penghalang satu dimensi 
Solusi persamaan Dirac tidak bergantung waktu memenuhi relasi

$$
H_{D}^{(1)} \psi=\epsilon \psi,
$$

diperoleh fungsi eigen yang berlaku untuk daerah I dan II adalah

$$
\psi\left(x_{1}, x_{2}\right)=\left(\begin{array}{c}
+i u_{n}^{+}|n+1\rangle \\
u_{n}|n\rangle \\
u_{n}^{+}|n\rangle \\
-i u_{n}^{-}|n-1\rangle
\end{array}\right) e^{i k_{1} x_{1}}
$$

dengan nilai representasi energinya sebesar

$$
\epsilon=\sqrt{n \hbar^{2} \omega_{k}^{2}+\frac{1}{4}\left(g \mu_{B} B\right)^{2}} ; n=0,1,2 \ldots
$$

\subsubsection{Spektrum Area II}

Dari persamaan (28) diperoleh

$$
H_{D}^{(2)}=v_{f}\left(\begin{array}{cc}
t^{\prime} & p_{1}-i p_{2}-\frac{\hbar}{l_{B}^{2}} \xi x_{2} \\
p_{1}+i p_{2}-\frac{\hbar}{l_{B}^{2}} \bar{\xi} x_{2} & -t^{\prime}
\end{array}\right)+\frac{1}{2} g \mu_{B} B \sigma_{3},
$$

dengan prosedur yang sama pada bagian sebelumnya, matriks pada persamaan (36) didiagonalisasi dengan menggunakan operator anihilasi dan kreasi dan selanjutnya diperoleh matriks sebagai berikut

$$
H_{D}^{(2)}=v_{f}\left(\begin{array}{cc}
t^{\prime}+\frac{1}{2} g \mu_{B} B & i \hbar \omega_{k} a^{\dagger} \\
-i \hbar \omega_{k} a & -t^{\prime}-\frac{1}{2} g \mu_{B} B
\end{array}\right) .
$$

Persamaan (37) untuk mencari spektrum energi dan spinor eigen serupa dengan potensial penghalang sebesar $V$ dengan mengoperasikan persamaan Dirac tidak bergantung waktu yang memenuhi

$$
H_{D}^{(2)} \psi=(\epsilon-V) \psi
$$

solusi persamaan (38) adalah

$$
\psi\left(x_{1}, x_{2}\right)=\phi\left(x_{2}\right) e^{q_{1} x_{1}}
$$

dengan $\varphi\left(x_{2}\right)=\left(\begin{array}{l}\left|\varphi_{1}\right\rangle \\ \left|\varphi_{2}\right\rangle\end{array}\right)$

Dari persamaan (37) dan (38) diperoleh

$$
\begin{aligned}
& i \hbar \omega_{k} a^{\dagger}\left|\varphi_{2}\right\rangle=\left(\epsilon^{\prime}-t^{\prime}-\frac{1}{2} g \mu_{B} B\right)\left|\varphi_{1}\right\rangle, \\
& -i \hbar \omega_{k} a\left|\varphi_{1}\right\rangle=\left(\epsilon^{\prime}-t^{\prime}+\frac{1}{2} g \mu_{B} B\right)\left|\varphi_{2}\right\rangle,
\end{aligned}
$$

dengan $\epsilon^{\prime}=\epsilon-V$. Dari persamaan (40) dan (41), $\left|\varphi_{2}\right\rangle$ disubstitusikan ke $\left|\varphi_{1}\right\rangle$ sehingga diperoleh

$$
\epsilon_{n_{ \pm}}^{\prime}=t^{\prime} \pm \sqrt{\left(\frac{1}{2} g \mu_{B} B\right)^{2}+n \hbar^{2} \omega_{k}^{2}} \quad \text { dengan } n=0,1,2, \ldots
$$


Persamaan (42) merupakan spektrum energi dari nilai eigen yang memiliki bentuk seperti osilator harmonik [19]. Oleh karena itu bentuk fungsi eigen sebagai berikut

$$
\left.\left|\varphi_{1}^{+}\right\rangle=\left|n>=\left(\frac{l_{B}}{\hbar}\right)^{n} \frac{\left(-i p_{1}-p_{2}+i \frac{\hbar}{l_{B}^{2}} \bar{\xi} x_{2}\right)^{n}}{\sqrt{2^{n} n !}}\right| 0\right\rangle,
$$

dan

$$
\begin{gathered}
\left|\varphi_{2}^{+}\right\rangle=-\frac{i \hbar \omega_{k} a}{\left(\epsilon^{\prime}+t^{\prime}+\frac{1}{2} g \mu_{B} B\right)}|n\rangle, \\
\left|\varphi_{2}^{+}\right\rangle=-i \sqrt{\frac{\left(\epsilon^{\prime}-t^{\prime}-\frac{1}{2} g \mu_{B} B\right)}{\left(\epsilon^{\prime}+t^{\prime}+\frac{1}{2} g \mu_{B} B\right)}}|n-1\rangle .
\end{gathered}
$$

Fungsi eigen spinor untuk energi positif (44) adalah

$$
\left|\varphi_{n}^{+}\right\rangle=\left(\begin{array}{c}
v_{n}^{+}|n\rangle \\
-i v_{n}^{+}|n-1\rangle
\end{array}\right),
$$

dengan nilai $v_{n}^{ \pm}$adalah

$$
v_{n}^{ \pm}=\left(\frac{1}{2} \pm \frac{t^{\prime}+\frac{1}{4} g \mu_{B} B}{\sqrt{\left(\frac{1}{2} g \mu_{B} B\right)^{2}+n \hbar^{2} \omega_{k}^{2}}}\right)^{\frac{1}{2}},
$$

sementara untuk energi negatif dengan pendekatan yang sama diperoleh fungsi eigen spinor yaitu

$$
\left|\varphi_{n}^{-}\right\rangle=\left(\begin{array}{c}
i v_{n}^{+}|n+1\rangle \\
v_{n}^{-}|n\rangle
\end{array}\right),
$$

sehingga solusi fungsi eigen untuk area II adalah

$$
\psi\left(x_{1}, x_{2}\right)=\left(\begin{array}{c}
v_{n}^{+}|n\rangle \\
-i v_{n}^{+}|n-1\rangle \\
i v_{n}^{+}|n+1\rangle \\
v_{n}^{-}|n\rangle
\end{array}\right) e^{q_{1} x_{1}}
$$

Sejauh ini, kalkulasi masih difokuskan pada penentuan energi dan solusi pada masing-masing area dimana untuk area I dan area III solusi yang diberikan merupakan fungsi sinusoidal sedangkan untuk area II solusinya bersifat eksponensial. Solusi fungsi eigen pada hasil penelitian ini memiliki bentuk yang serupa dengan beberapa penelitian sebelumnya $[16,18]$ akan tetapi dengan pendekatan berbeda yaitu memunculkan operator kreasi dan anhilasi sebagaimana perhitungan secara eksak pada kasus osilator harmonik. Untuk selanjutnya, fungsi eigen yang diperoleh dapat menentukan koefisien transmisi dan refleksi.

\section{Kesimpulan}

Penelitian ini bertujuan untuk mengkaji karakter suatu partikel yang melewati suatu potensial penghalang di bawah pengaruh medan elektromagnetik. kajian yang telah dilakukan merupakan kajian analitik dalam teori kuantum relativitas. Berdasarkan hasil penurunan formulasi dan analisis matematis menghasilkan gambaran perilaku partikel pada potensial penghalang dengan pengaruh medan elektromagnetik.

Penyelesaian pada area I dan III dengan memperkenalkan operator anihilasi dan kreasi seperti pada kasus osilator harmonik telah menghasilkan spektrum energi sebagai nilai eigen pada persamaan (35). Spektrum energi bernilai positif dan negatif dengan fungsi eigen yang ditunjukkan pada persamaan (34). Pada area II spektrum energi yang dihasilkan juga bernilai postif dan negatif ditunjukkan 
persamaan (42) dengan fungsi eigennya seperti pada persamaan (49). Area I dan III jika dibandingkan dengan area II memiliki perbedaan yaitu bentuk spektrum energi pada area II memiliki bentuk yang lebih umum dan jika diaproksimasikan dengan menghilangkan penghalang $\left(t^{\prime} \approx 0\right)$ maka akan didapati nilai spektrum energi mirip dengan area I dan III.

\section{Ucapan Terima Kasih}

Ucapan terima kasih disampaikan kepada semua pihak yang telah membantu dalam penyusunan naskah artikel ini khususnya Lembaga Penelitian dan Pengabdian Masyarakat UIN Maulana Malik Ibrahim Malang dan Direktorat Pendidikan Tinggi Islam Ditjen Pendis Kementrian Agama RI melalui Bantuan Penelitian tahun 2018.

\section{Daftar Rujukan}

[1] S. J. Woltornist et al., "Conductive Thin Films of Pristine Graphene by Solvent Interface Trapping”, ACS Nano, vol. 7, no. 8, pp. 7062-7066, 2013

[2] H. W. Kim et al., "Selective Gas Transport Through Few-Layered Graphene and Graphene Oxide Membranes", Science, vol. 342, no. 6154, pp. 91-95, 2013.

[3] S. K. Alen, S. W. Nam, and S. A. Dastgheib, "Recent Advances in Graphene Oxide Membranes for Gas Separation Applications", Int. J. of Molecular Sci., vol. 20, no. 22, pp. 1-20, 2019.

[4] M. Barbier et al., "Dirac and Klein-Gordon Particles in One-Dimensional Periodic Potentials", Phy. Rev. B - Condensed Matter and Materials Phy., vol. 77, no. 11, pp. 1-9, 2008.

[5] Y. Zheng and T. Ando, "Hall Conductivity of A Two-Dimensional Graphite System", Phy. Rev. B-Condensed Matter and Materials Phy., vol. 65, no. 24, pp. 2454201-24542011, 2002.

[6] S. Ganguly and J. J. Ghosh, "Steroid Hormone Induced Alterations in Endometrium: I. Changes in Lipid Content, Swelling Pattern \& Lipid Peroxidation of Mitochondria", Indian J. of Biochemistry and Biophysics, vol. 16, no. 2, pp. 61-65, 1979.

[7] V. P. Gusynin and S. G. Sharapov, "Unconventional Integer Quantum Hall Effect in Graphene", Phy. Rev. Lett., vol. 95, no. 14, pp. 1-4, 2005.

[8] M. I. Katsnelson, K. S. Novoselov, and A. K. Geim, "Chiral Tunnelling and The Klein Paradox in Graphene", Nature Physics, vol. 2, no. 9, pp. 620-625, 2006.

[9] A. Jellal et al., "Tunneling of Massive Dirac Fermions in Graphene Through Time-Periodic Potential", European Phy. J. B, vol. 87, no. 6, pp. 1-19, 2014.

[10] M. A. Zeb, K. Sabeeh, and M. Tahir, "Chiral Tunneling Through A Time-Periodic Potential in Monolayer Graphene", Phy. Rev. B-Condensed Matter and Materials Phy., vol. 78, no. 16, pp. $1-7,2008$.

[11] C. Bai and X. Zhang, "Klein Paradox and Resonant Tunneling in A Graphene Superlattice", Phy. Rev. B-Condensed Matter and Materials Phy., vol. 76, no. 7, pp. 1-7, 2007.

[12] T. Das and A. Arda, "Klein-Gordon Equation for A Charged Particle in Space Varying Electromagnetic Fields-A Systematic Study Via Laplace Transform", Chinese J. of Phy., vol. 55, no. 2, pp. 310-317, 2017.

[13] B. Hamil and L. Chetouani, "Moving Potential for Dirac and Klein-Gordon Equations", Pramana - J.l of Phy., vol. 86, no. 4, pp. 737-746, 2016.

[14] A. D. Alhaidari, H. Bahlouli, and A. Jellal, "Confined Dirac Particles in Constant and Tilted Magnetic Field", Int. J. of Geometric Methods in Modern Phy., vol. 12, no. 05, p. 1550062, 2015.

[15] A. Jellal, A. D. Alhaidiri, and H. Bahlouli, "Confined Dirac Fermions in A Constant Magnetic Field", Phy. Rev. A, vol. 80, no. 1, p. 012109, 2009.

[16] E. B. Choubabi, M. E. Bouziani, and A. Jellal, "Tunneling for Dirac Fermions in Constant Magnetic Field", Int. J. of Geometric Methods in Modern Phy., vol. 7, no. 6, pp. 909-931, 2010.

[17] M. I. Katsnelson and K. S. Novoselov, "Graphene: New Bridge Between Condensed Matter Physics and Quantum Electrodynamics", Solid State Comm., vol. 143, no. 1-2, pp. 3-13, 2007.

[18] K. Bhattacharya, Solution of The Dirac Equation in Presence of An Uniform Magnetic Field, Mexico, Universidad Nacional Autonoma de Mexico, 2008.

[19] O. Philipsen, "An Introduction to Quantum Field Theory", In Proc. of the School for Experimental High Energy Phy. Students, 2006.

[20] D. Griffiths, Introduction to Elementary Particles, Weinheim, John Wiley \& Sons, 2008 
[21] H. Kleinert, "Relativistic Particles and Fields in External Electromagnetic Potential", Particles and Quantum Fields, vol. 2, pp. 436-473, 2016.

[22] A. Jellal, A. E. Mouhafid, and M. Daoud, "Massless Dirac Fermions in An Electromagnetic Field", J. of Statistical Mech.: Theory and Experiment, vol. 1, 2012. 